\title{
The Family Physician's Role in End-of-Life Care
}

\author{
Tessa Robrberg, MD, Resident Representative, Editorial Advisory Board \\ Ann Fam Med 2014;12(5):iii. doi:10.1370/afm.1695.
}

$\mathrm{T}$

The Annals of Family Medicine encourages readers to develop a learning community of those seeking to improve health care and health through enhanced primary care. You can participate by conducting a RADICAL journal club and sharing the results of your discussions in the Annals online discussion for the featured articles. RADICAL is an acronym for Read, Ask, Discuss, Inquire, Collaborate, Act, and Learn. The word radical also indicates the need to engage diverse participants in thinking critically about important issues affecting primary care and then acting on those discussions. ${ }^{1}$

\section{HOW IT WORKS}

In each issue, the Annals selects an article or articles and provides discussion tips and questions. We encourage you to take a RADICAL approach to these materials and to post a summary of your conversation in our online discussion. (Open the article online and click on "TRACK Comments: Submit a response.") You can find discussion questions and more information online at: http://www.AnnFamMed.org/site/AJC/.

\section{CURRENT SELECTION}

\section{Article for Discussion}

Reyniers T, Houttekier D, Pasman HR, Vander Stichele R, Cohen J, Deliens $\mathrm{L}$. The family physician's perceived role in preventing and guiding hospital admissions at the end of life: a focus group study. Ann Fam Med. 2014;12(5):4441-446.

\section{Discussion Tips}

This article provides a qualitative look at how family physicians in Belgium perceive their roles in preventing and guiding hospitalization near the end of patients' lives. The study provides an opportunity to consider 5 key roles that family physicians can play at the end of life, and to learn from differences among health systems and cultures.

\section{Discussion Questions}

- What question is asked by this study and why does it matter?

- How does this study advance beyond previous research and clinical practice on this topic?

- How strong is the study design for answering the question?

- What other study designs could be used to answer the question?

- To what degree can the findings be accounted for by: 1. How physicians were selected or excluded?

2. How the questions were asked? Were the researchers leading?

3. How the findings were interpreted?

4. How the findings were reported?

- What are the main study findings? How well do the quotations support the identified themes?

- How comparable is the study sample to similar physicians in your practice? What is your judgment about the transportability of the findings?

- What contextual factors are important for interpreting the findings? How might culture play a role in interpretation?

- How might this study change your practice? Policy? Education? Research?

- Who the constituencies are for the findings, and how they might be engaged in interpreting or using the findings?

- What are the next steps in interpreting or applying the findings?

- How might these findings be used to create a quantitative study?

- What researchable questions remain?

\section{References}

1. Stange KC, Miller WL, McLellan LA, et al. Annals Journal Club: It's time to get RADICAL. Ann Fam Med. 2006;4(3):196-197. http:// annfammed.org/cgi/content/full/4/3/196. 